\title{
Feeding of the chaetognaths Sagitta elegans and S. setosa at different seasons in Gullmarsfjorden, Sweden
}

\author{
Vidar Øresland \\ Department of Zoology, University of Stockholm, S-106 91 Stockholm, Sweden
}

\begin{abstract}
Diel feeding regimes of Sagitta elegans and S. setosa were investigated by gut content analyses on 24301 Sagitta, taken in hourly plankton hauls during $24 \mathrm{~h}$ sampling programmes at different seasons. Feeding was most intensive at night in both species except for $S$. elegans in winter. Diet differed considerably between the species, $S$. elegans taking almost only copepods and $S$. setosa taking small copepods, nauplii, appendicularians and other $S$. setosa: the difference is believed to reflect differences in size (the larger $S$. elegans taking larger prey) and vertical distribution ( $S$. setosa taking smaller prey in the surface layer). The cannibalism of $S$. setosa, found during the breeding period in autumn, is believed to contribute to the sharp decrease in numbers of $S$. setosa at that time. Daily feeding rates (in numbers of different prey categories) of $S$. elegans were estimated by combining gut content analysis with digestion time data obtained in the laboratory at $6^{\circ} \mathrm{C}$. Mean digestion time varied from 9.3 to $4.9 \mathrm{~h}$ depending on prey category. Total feeding rate varied from 1.0 to 0.2 prey items $\mathrm{d}^{-1}$, being highest for the breeding generation in spring and lowest for the immature generation in autumn and winter. Total feeding rate of $S$. setosa in autumn was estimated to be roughly 2.3 items $\mathrm{d}^{-1}$.
\end{abstract}

\section{INTRODUCTION}

Chaetognaths are probably one of the main sources of predation pressure on the copepod community and are believed to have considerable influence on the size structure of lower trophic levels (Pearre 1980). The literature concerning chaetognath feeding has been reviewed by Feigenbaum \& Maris (1984). Additional papers are: Drits (1981), Nagasawa \& Marumo (1982, 1984), Terazaki \& Marumo (1982), Fulton (1984), Kimmerer (1984), Nagasawa (1984, 1985), Alvarino (1985). Canino \& Grant (1985), Ohman (1986). Estimates of feeding rates of chaetognaths based on a combination of gut content analysis of field samples and digestion times determined in the laboratory are increasingly becoming available. So far, however, such data exist only for a few chaetognath species and no data are available for chaetognaths from European shelf waters. The main reason for this lack of feeding rate data is due to the great difficulties involved in keeping most chaetognath species alive in the laboratory.

Sagitta elegans Verrill and S. setosa J. Müller (Fig. 1; showing their maximum size in Gullmarsfjorden) are

(C) Inter-Research/Printed in F. R. Germany the 2 dominant chaetognath species in European shelf waters. They are often vertically separated, $S$. setosa being more common in the upper $20 \mathrm{~m}$, and $S$. elegans being more common in deeper water, especially the larger specimens (Furnestin 1938, Jakobsen 1971, Southward \& Barret 1983). In Gullmarsfjorden, situated on the west coast of Sweden, the larger S. elegans (max. length $37 \mathrm{~mm}$ ) occurs throughout the year while the smaller $S$. setosa (max. length $15 \mathrm{~mm}$ ) is transported into the fjord in late summer and declines in abundance during autumn, winter and spring. Both species have a 1 yr life cycle on the Swedish west coast (Øresland 1983, 1985).

The gut content of Sagitta spp. from European shelf waters has earlier been studied by Lebour $(1922,1923)$, Wimpenny (1937), Rakusa-Suszczewski (1969) and Tungate (1975), while Kuhlmann (1977) did laboratory studies on the feeding behaviour of Sagitta. None of these studies give estimates of feeding rates based on field samples. In this study, the diel feeding of the 2 species is compared qualitatively and the $S$. elegans daily ration of different food items is estimated at all 4 seasons by combining gut content analysis with digestion time experiments. 


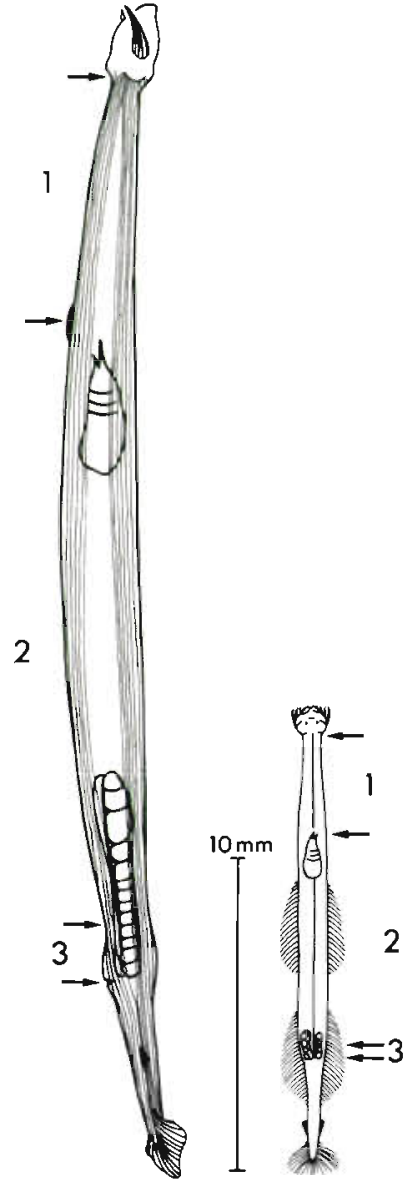

2

Fig. 1. Mature Sagitta elegans (left) and S. setosa (right) with copepods in their guts. The gut is divided into 3 sections: 1. forward; 2, middle; 3 , posterior

\section{MATERIALS AND METHODS}

Gullmarsfjorden $\left(58^{\circ} 19^{\prime} \mathrm{N} ; 11^{\circ} 33^{\prime} \mathrm{E}\right)$ and its hydrography are briefly described in Oresland (1985). Fig. 2 shows mean temperature profiles during 4 sampling occasions, measured 1 to 10 times using a field salinometer (Electronic Switchgear ${ }^{(3)}$ ). Chaetognath samples for gut content analyses were taken in the deepest $(125 \mathrm{~m})$ area of the fjord. Sampling was done over $24 \mathrm{~h}$ on 20 to $21 \mathrm{Apr}, 27$ to $28 \mathrm{Jul}, 4$ to $5 \mathrm{Oct}$ and 21 to 22 Dec 1982, and followed the same procedure as in Øresland (1985). Sampling dates were chosen in order to reflect differences in population mean length and age as well as in temperature and food conditions. A 10 to 15 min oblique haul, from the surface down to 0 to $15 \mathrm{~m}$ above the bottom and up to the surface again, was made approximately every hour. During night sampling all ship lights were tumed off. Sampling speed was $1 \mathrm{~m} \mathrm{~s}^{-1}$. The net, a 'Scherbrutnetz' (Ehrenbaum \& Strodtmann 1904), had a length of $2.8 \mathrm{~m}$ and a square opening of $0.5 \mathrm{~m}^{2}$. Mesh size was $450 \mu \mathrm{m}$ and cod-end mesh size was $250 \mu \mathrm{m}$ (in order to reduce flow and damage to chaetognaths). A depressor plane was mounted under the net frame and a bathythermograph,

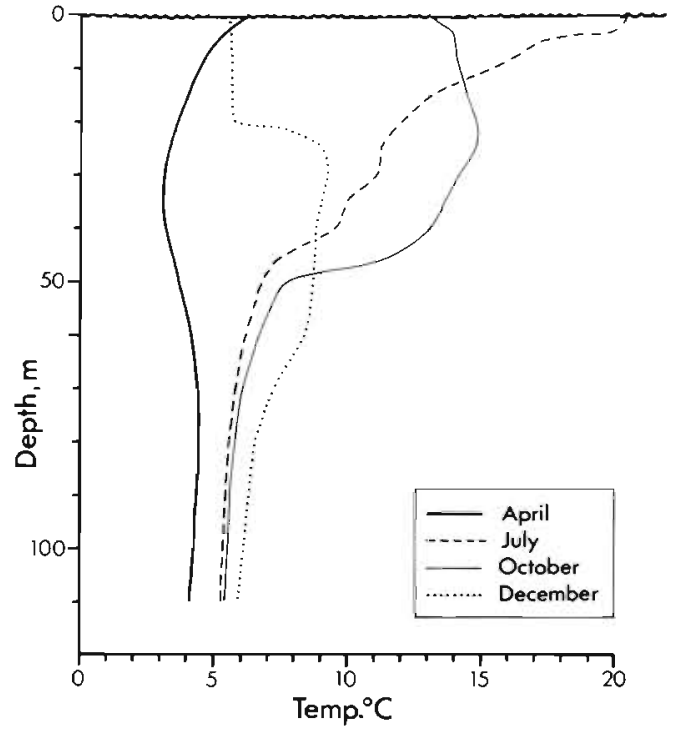

Fig. 2. Temperature profiles in Gullmarsfjorden during the 4 sampling occasions in 1982

measuring the maximum sampling depth, was mounted on the wire $2 \mathrm{~m}$ above the net. The net was not suited for quantitative sampling as the depressor plane created a current into the net. All samples were immediately preserved in $4 \%$ formaldehyde in seawater, buffered with borax.

The chaetognaths were in good condition when sorted and analyzed for gut content during 1985-1986. Most samples from July and October were subsampled using a splitting box (Motoda 1959) and one half to one quarter of the sample was analyzed. Chaetognaths ingest their prey whole. Food items can easily be seen in the gut due to the transparency of these chaetognath species. Chaetognaths which had not completely swallowed their prey were not included in further analyses. The length of all chaetognaths with possible food remains in the gut was measured to the nearest $\mathrm{mm}$ under a stereomicroscope, and then transferred to a few drops of polyvinyl-lactophenol on a microscope slide. The position in the gut of all prey items was noted according to Fig. 1, and all copepods whose prosome length could easily be measured were noted as undigested. Prey items were dissected using needles made of tungsten wire sharpened in melted $\mathrm{NaNO}_{2}$. The mandible pairs of partly or fully digested copepodites and nauplii were counted and the width of the mandibular blades was measured under an inverted microscope. Mandibles with a width $\geq 0.10 \mathrm{~mm}$ could be identified as belonging to either Calanus IV to VI or Temora V to VI. Mandibles with a width $<0.10 \mathrm{~mm}$ were referred to as belonging to earlier developmental stages or other genera of copepods or nauplii (mainly of copepods). Appendicularians were detected by their fecal pellets, which resist digestion in the Sagitta gut. 
No more than 3 pellets were found simultaneously in the gut and they were always assumed to originate from a single appendicularian. Prey chaetognaths were recognized by their grasping spines.

The daily feeding rate (in numbers of different food categories) of Sagitta elegans was estimated using the equation (Bajkov 1935):

$$
\mathrm{FR}=\frac{\text { mean } \mathrm{NPC} \times 24}{\mathrm{DT}}
$$

where $F R=$ daily feeding rate (no. prey $\mathrm{d}^{-1}$ ) (each category of prey is estimated separately in this study); mean NPC = mean number of a certain prey category per chaetognath (or carnivore) during a $24 \mathrm{~h}$ period; DT = digestion time $(\mathrm{h})$ for a certain category. Multiplication by 24 gives the daily feeding rate. See Feigenbaum \& Maris (1984) for a discussion of the equation.

In order to obtain mean NPC values for different prey categories, the numbers of prey per chaetognath (NPC) obtained from the different samples during the $24 \mathrm{~h}$ sampling periods were plotted for both species (Fig. 3 \& 4). The mean height of the curve connecting the NPC plots is equal to the mean NPC. The mean height of the curves could be calculated by taking 5 photocopies of each curve, cutting them out and weighing them on a microbalance, and dividing their weight by the weight of a known area of the same paper.

Laboratory feeding experiments were carried out at Tjärnö Marine Biological Station, $70 \mathrm{~km}$ north of Gullmarsfjorden, during June, July and October 1985, and in April 1986, in order to obtain DT values for Sagitta elegans at different seasons. No experiments could be carried out during the winter due to ice conditions. Chaetognaths are generally extremely difficult to keep in the laboratory. I therefore concentrated my effort on $S$. elegans which was collected in Kosterfjorden. A $1 \mathrm{~m}$ net, mesh size $200 \mu \mathrm{m}$, with a large cod-end bucket in which a $12 \mathrm{l}$ grey plastic bag was secured, was hauled vertically at approximately $10 \mathrm{~cm} \mathrm{~s}^{-1}$ from $200 \mathrm{~m}$ to $50 \mathrm{~m}$ where the net was closed. On board the ship the plastic bag was closed and transferred to a water bath at 4 to $6^{\circ} \mathrm{C}$. Using this method a minimum of handling of the chaetognaths was achieved and several hauls could be made using the same large cod-end bucket.

In the laboratory (constant-temperature room, $6^{\circ} \mathrm{C}$ ) Sagitta elegans were sorted using a large spoon and transferred to 61 aquaria with seawater $\left(6^{\circ} \mathrm{C}, 33\right.$ to $34 \% \mathrm{~S})$ and $90 \mu \mathrm{m}$ net plankton as food, and kept for a maximum of $5 \mathrm{~d}$ before an experiment. Half of the water volume was exchanged every second day. Water circulation was created by directing a jet of compressed air towards the water surface. High frequency vibrations from the cooling apparatus were prevented by putting the aquaria on $15 \mathrm{~cm}$ foam rubber. Specimens were kept under $12 / 12 \mathrm{~h}$ dark-light conditions using a
$40 \mathrm{~W}$ green light bulb directed towards the ceiling. Ten $h$ before an experiment started about $20 \mathrm{~S}$. elegans in seemingly good condition were transferred to another $6 \mathrm{l}$ aquarium with $20 \mu \mathrm{m}$ filtered seawater. When the experiments started (normally at about $2300 \mathrm{~h}$ ) newly caught zooplankton was added and the $S$. elegans were watched for $30 \mathrm{~min}$. S. elegans taking prey were individually isolated in $200 \mathrm{ml}$ aquaria with $20 \mu \mathrm{m}$ filtered seawater, and after 3 to $6 \mathrm{~h}$ they were observed every 10 to $15 \mathrm{~min}$ until the food remains were defaecated. Digestion time (=gut clearance time) was defined as the time when food was present in the gut, i.e. the actual swallowing time of the food was not included. The food items were easily identified when still undigested using a stereo microscope. The experiments were carried out in darkness except for the first 30 min when zooplankton was given and when isolated $S$. elegans were checked for food remains in their guts (a stereomicroscope lamp was used for chaetognath inspection). A water temperature of $6.0^{\circ} \mathrm{C}\left( \pm 0.5 \mathrm{C}^{\circ}\right)$ was chosen for all experiments, being fairly close to the mean temperature which $S$. elegans experiences below $50 \mathrm{~m}$ in Gullmarsfjorden (Fig. 2).

\section{RESULTS}

\section{Sagitta elegans}

Fig. 3. shows the NPC data for Sagitta elegans in the different seasons (uncommon prey categories excluded). These data show the variation in feeding intensity on different prey categories during $24 \mathrm{~h}$ and are also used to obtain the mean NPC values which will be used when calculating daily feeding rate (FR). The first values have been used also as last values in order to draw the curves through $24 \mathrm{~h}$.

In April the Sagitta elegans population was clearly separated into 2 generations with quite different median lengths. The NPC data of the 2 generations are therefore shown separately. The old generation with $\geq 20 \mathrm{~mm}$ long specimens (median length $28 \mathrm{~mm}$ ) showed a high increase in feeding around sunset and a decrease around sunrise. Copepods made up $98 \%$ of the gut content. Of the remaining $2 \%, 9$ items were unidentified and 4 items were $S$. elegans belonging to the new generation (determined by the length of the longest hook). The new generation with $<20 \mathrm{~mm}$ long specimens (median length $11 \mathrm{~mm}$ ) showed a similar diel feeding behaviour. Copepods made up $96 \%$ of the gut content. Of the remaining $4 \%, 3$ items were nauplii and 8 items were unidentified. In contrast to the old generation, the gut content was dominated by small copepods, and large copepods, Calanus and Temora spp., were taken only by specimens close to $20 \mathrm{~mm}$ in length. 


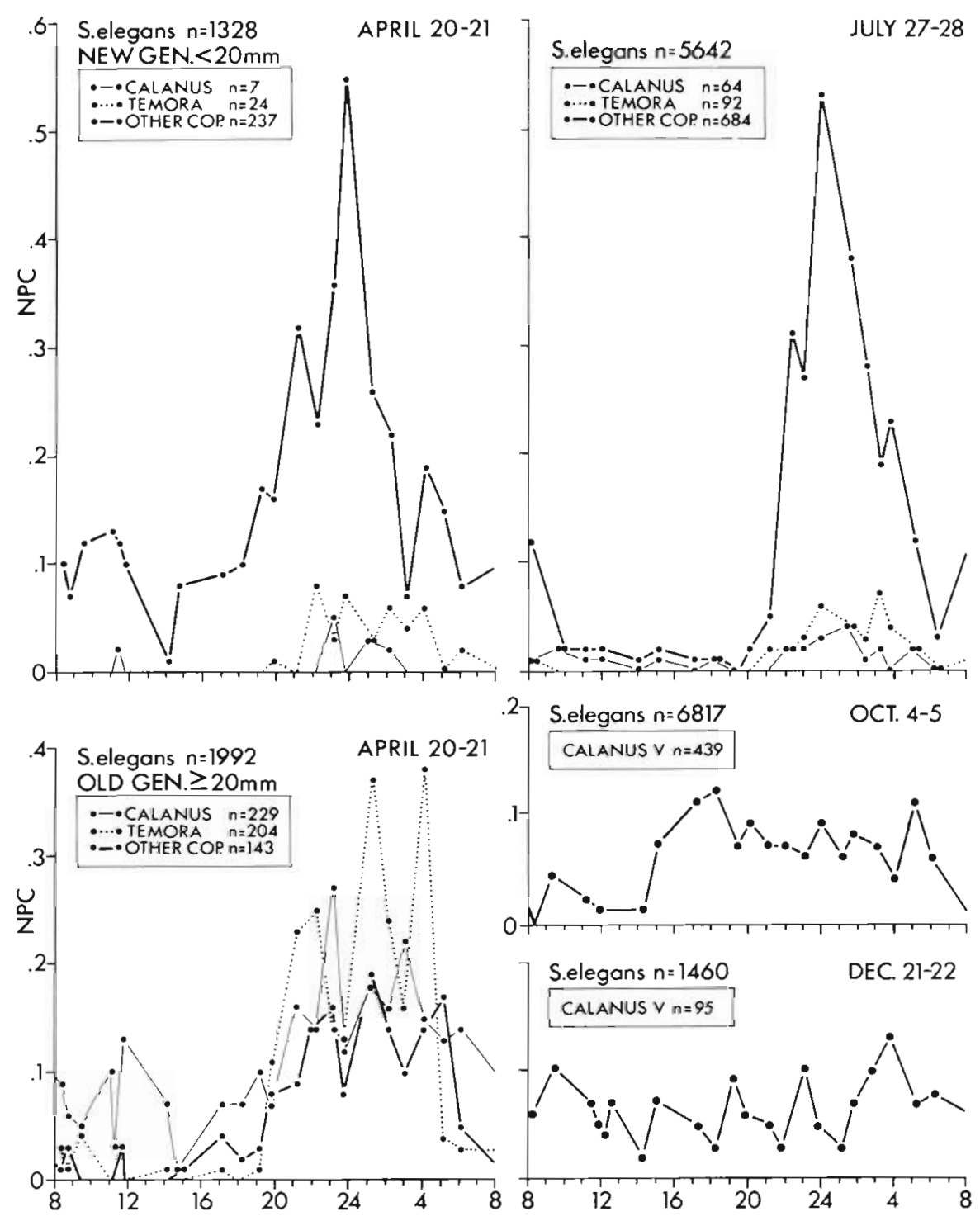

Fig. 3. Sagitta elegans. Number of prey per chaetognath (NPC) during $24 \mathrm{~h}$ for different prey items at 4 different seasons during 1982. In April values are given for 2 different generations. Period between sunset and sunrise is indicated by dark bar. In Calanus (IV to VI) and Temora (V to $\mathrm{VI}$ ) only prey with a mandibular width $\geq 0.10 \mathrm{~mm}$ are included. All other specimens are included in copepods (cop.)

In July the older generation had disappeared and the median length of the younger generation had increased to $18 \mathrm{~mm}$. Gut content and feeding behaviour were quite similar to that found for this generation in April, but the increase in feeding rate at sunset was much sharper. Copepods made up $98 \%$ of the gut content. Of the remaining $2 \%, 12$ items were nauplii, 1 was a cladoceran Podon sp. and 2 items were unidentified. Again large copepods were taken only by the largest specimens.

In October the median length was $24 \mathrm{~mm}$ and $94 \%$ of the gut content was made up of Calanus spp.; of the remaining $6 \%, 22$ items were small copepods, 1 was a Temora sp., 2 were nauplii and 4 were unidentified. High frequencies of undigested food items (29 to $35 \%$ ) were found simultaneously with the increase of NPC during the afternoon. A few undigested food items could, however, be found at almost any time.

In December the median length was $27 \mathrm{~mm}$ and $84 \%$ of the gut content was made up of large Calanus spp. and of the remaining $16 \%, 16$ items were small copepod species and 2 were Temora spp. Calanus spp. were found in nearly the same frequency throughout the sampling period. Only 7 undigested copepods were found, so no particular period of increased feeding activity could be detected.

\section{Sagitta setosa}

Fig. 4 shows the NPC data for Sagitta setosa in October and December (uncommon Calanus and Te- 
mora spp. excluded). S. setosa reproduces during autumn, i.e. 2 generations are present (Øresland 1983). Therefore a wide size spectrum of 1 to $15 \mathrm{~mm}$ (median $7 \mathrm{~mm}$ ) was found in October. Feeding increased around sunset and declined around sunrise indicated by the NPC curves and the occurrence of undigested food. Striking differences in the diet between the 2 Sagitta species were found in October. For S. setosa,
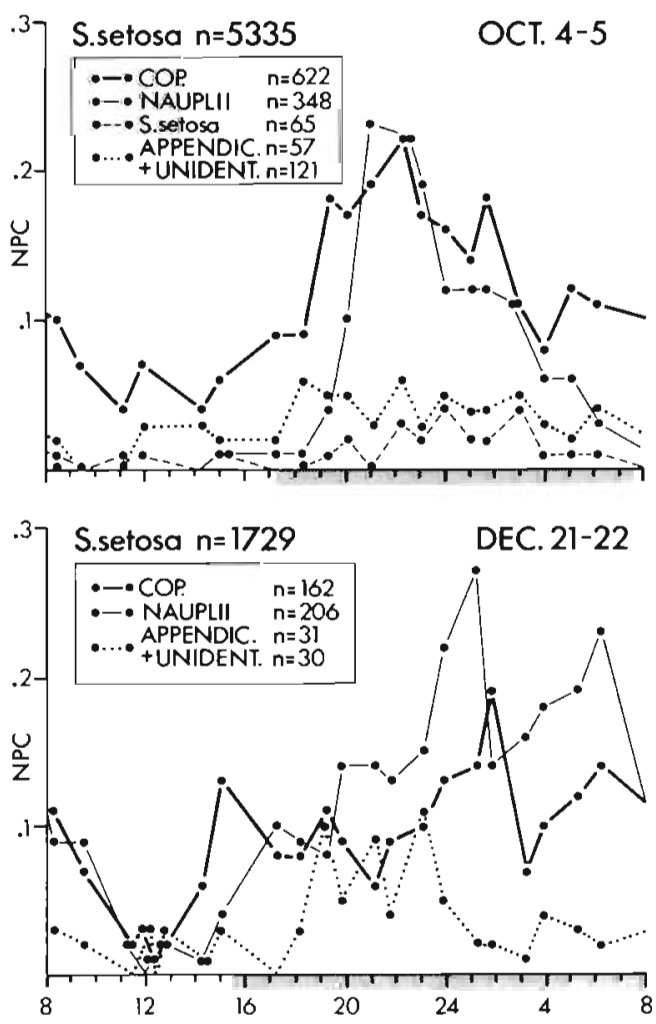

Fig. 4. Sagitta setosa. Number of prey per chaetognath (NPC) during $24 \mathrm{~h}$ for different prey items at 2 different seasons during 1982. Period between sunset and sunrise is indicated by dark bar
$52 \%$ of the gut content was made up of copepods, $28 \%$ was nauplii and $15 \%$ was appendicularians including unidentified items. The remaining $5 \%$ consisted of $S$. setosa, i.e. cannibalism was found. Only low numbers of larger copepods (19 Calanus spp. and 7 Temora spp.) were found in $S$. setosa. The mean length of the $S$. setosa cannibals was $8.4 \mathrm{~mm}$ (range 5 to $11 \mathrm{~mm}, \mathrm{n}=60$ ). The mean length of the longest hook of S. setosa prey was $0.20 \mathrm{~mm}$ (range 0.10 to $0.31 \mathrm{~mm}, \mathrm{n}=$ $60)$ corresponding to a mean prey length of about $5 \mathrm{~mm}$. Size distributions of $S$. setosa and $S$. elegans were almost entirely separated in October. The hooks found in $S$. setosa were too short to originate from $S$. elegans.

In December the median length of Sagitta setosa had increased to $9 \mathrm{~mm}$ and the annual decrease in abundance had started. Diel feeding behaviour of $S$. setosa was obvious also in December (in contrast to $S$. elegans). A second increase in feeding rate during the morning, indicated by the NPC curves and many undigested prey items, was evident. It is notable that only 2 $S$. setosa were found as prey.

\section{Daily feeding rate}

The necessary data for calculating the FR of Sagitta elegans are given in Table 1 (mean NPC data obtained from the NPC curves in Fig. 3) and Table 3 (DT data from Iaboratory experiments). Table 4 shows the FR for $S$. elegans, calculated separately for each prey category. Note the high FR values on Calanus and Temora spp. for the old generation and the change in diet of the new generation throughout the year. No DT experiments were carried out on $S$. setosa. By combining the total mean NPC value of $S$. setosa in October (Table 2) with a DT of $2.3 \mathrm{~h}$ (137 min) obtained by Kuhlmann (1977) on copepods for Sagitta at $15^{\circ} \mathrm{C}$, a total FR of 2.3

Table 1 Sagitta elegans. Mean number of prey items per chaetognath mean NPC during $24 \mathrm{~h}$, based on curves shown in Fig. 3

\begin{tabular}{|c|c|c|c|c|c|}
\hline & $\begin{array}{l}\text { April } \\
\text { Old generation }\end{array}$ & $\begin{array}{c}\text { April } \\
\text { New generation }\end{array}$ & July & October & December \\
\hline $\begin{array}{l}\text { Median length of } \\
\text { S. elegans }(\mathrm{mm})^{\circ}\end{array}$ & 28 & 11 & 18 & 24 & 27 \\
\hline \multicolumn{6}{|l|}{ Food items } \\
\hline Calanus IV-VI & 0.114 & 0.005 & 0.012 & 0.059 & 0.069 \\
\hline Temora V-VI & 0.099 & 0.018 & 0.015 & & \\
\hline Remaining copepods & 0.065 & 0.161 & 0.123 & & \\
\hline Total & 0.278 & 0.184 & 0.150 & 0.059 & 0.069 \\
\hline No. of food items & 576 & 268 & 840 & 439 & 95 \\
\hline No. of analysed S. elegans & 1992 & 1328 & 5642 & 6817 & 1460 \\
\hline
\end{tabular}


Table 2. Sagitta setosa. Mean number of prey items per chaetognath (mean NPC) during $24 \mathrm{~h}$, based on curves shown in Fig. 4

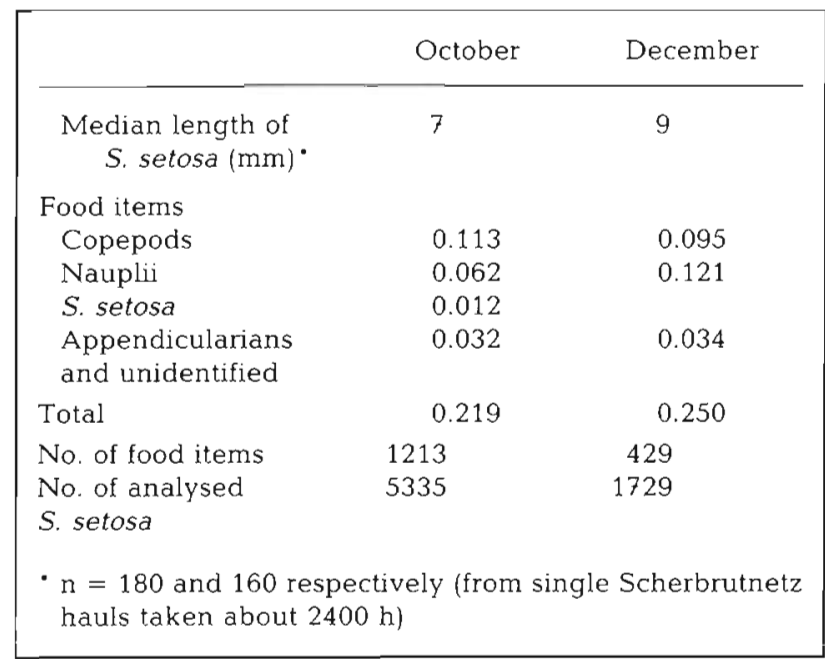

is obtained. Mean temperatures experienced by $S$. setosa in the upper $20 \mathrm{~m}$ in October and December were approximately 14 and $6^{\circ} \mathrm{C}$ respectively (Fig. 1). No FR calculations can be made for $S$. setosa in December due to lack of suitable DT data.

The FR calculations are assumed here not to be affected by whether the prey occurs singly or together with other prey items. Since little knowledge exists about the effect of multiple prey on DT, the frequency of multiple prey is given in Tables $5 \& 6$, so alternative calculations can be done when new DT data becomes available. Not surprisingly, small food items were the most common multiple prey. Calanus spp. seldom occurred together with other prey, but in April a maximum of 4 Calanus was found in one $29 \mathrm{~mm}$ long $S$. elegans. The highest number of prey items ever found was for S. elegans; 6 Temora and 3 smaller copepods in an $18 \mathrm{~mm}$ long specimen in July and for $S$. setosa; 2 copepods, 2 nauplii and 1 unidentified item in a $10 \mathrm{~mm}$ long specimen in October.

\section{DISCUSSION}

\section{Methods}

Estimates of feeding rates can be obtained by various methods (see Feigenbaum \& Maris 1984). The most straightforward method is by combining gut content analysis from field samples with digestion time data obtained in the laboratory. The factors that could bias feeding studies of this kind are the representativeness of the chaetognath size frequency distribution, gut contents, gut analyses and the estimated digestion times. The reliability of the sampling procedure in obtaining
Table 3. Sagitta elegans. Digestion times (DT) with different food items, obtained in laboratory experiments, at $6^{\circ} \mathrm{C}$

\begin{tabular}{|c|c|c|c|c|}
\hline Date & $\begin{array}{l}\text { Length } \\
(\mathrm{mm})\end{array}$ & Stage & Prey ${ }^{\circ}$ & $\begin{array}{l}\text { Digestion } \\
\text { time (min) }\end{array}$ \\
\hline \multirow[t]{5}{*}{$2 \mathrm{Apr}$} & 22 & III & Calanus & 475 \\
\hline & 23 & III & Calanus & 440 \\
\hline & 25 & III & Calanus & 410 \\
\hline & 23 & III & Calanus & 654 \\
\hline & & & & $\begin{array}{c}\text { Mean: } \\
495=8.25 h\end{array}$ \\
\hline \multirow{18}{*}{$\begin{array}{l}14 \mathrm{Jun} \\
\text { to } 5 \mathrm{Jul}\end{array}$} & 19 & III & Calanus & 511 \\
\hline & 15 & II & Calanus & 406 \\
\hline & 19 & III & Calanus & 662 \\
\hline & 21 & II & Calanus & 642 \\
\hline & 16 & II & Calanus & 542 \\
\hline & 20 & II & Calanus & 602 \\
\hline & 20 & II & Calanus & 545 \\
\hline & 19 & III & Calanus & 505 \\
\hline & 16 & II & Calanus & 626 \\
\hline & 18 & II & Calanus & 407 \\
\hline & & & & $\begin{array}{c}\text { Mean: } \\
545=9.08 \mathrm{~h}\end{array}$ \\
\hline & 19 & II & Copepod & 267 \\
\hline & 18 & III & Copepod & 363 \\
\hline & 15 & II & Copepod & 301 \\
\hline & 16 & Il & Copepod & 245 \\
\hline & & & & Mean: \\
\hline & & & & $294=4.90 \mathrm{~h}$ \\
\hline & 21 & III & Temora & $362=6.03 \mathrm{~h}$ \\
\hline \multirow{11}{*}{$\begin{array}{l}17 \text { to } 30 \\
\text { Oct }\end{array}$} & 25 & II & Calanus & 665 \\
\hline & 23 & II & Calanus & 675 \\
\hline & 26 & II & Calanus & 759 \\
\hline & & & & Mean: \\
\hline & 23 & II & Copepod & 501 \\
\hline & 19 & II & Copepod & 455 \\
\hline & 18 & II & Copepod & 500 \\
\hline & & & & Mean: \\
\hline & & & & $485=8.08 \mathrm{~h}$ \\
\hline & & & & Mean all Calanus: \\
\hline & & & & $560=9.33 \mathrm{~h}$ \\
\hline \multicolumn{5}{|c|}{$\begin{array}{l}\text { - Calanus spp. were in Stage IV to VI and Temora spp. } \\
\text { Stage VI. 'Copepod' represents smaller stages or other } \\
\text { copepod genera }\end{array}$} \\
\hline
\end{tabular}

samples reflecting the true size frequency distribution is discussed in Øresland (1985). The sampling is biased with regard to the smallest size classes of both species. The sometimes sharp NPC curves demonstrate the importance of frequent sampling in this study in order to obtain useful estimates of mean NPC. Cod-end feeding, voiding and defaecation of gut content during handling and preservation might bias the results (see Feigenbaum \& Maris 1984). In this study, cod-end feeding is not regarded as important. This is due to the low frequency of food items found in the forward part of the gut $(5,3,2$ and $0 \%$ in Sagitta elegans and 1 and $0 \%$ in S. setosa at the different seasons) and the short 
Table 4. Sagitta elegans. Daily feeding rate (FR) in no. of prey items. Gullmarsfjorden, 1982. Digestion times assumed for Calanus spp., Temora spp. and remaining copepods are $9.33,6.03$ and $4.90 \mathrm{~h}$ respectively (from Table 3 )

\begin{tabular}{|lccccc|}
\hline Prey & $\begin{array}{c}\text { Apri } \\
\text { Old generation }\end{array}$ & $\begin{array}{c}\text { April } \\
\text { New generation }\end{array}$ & July & October & December \\
\hline Calanus IV-VI & 0.29 & 0.01 & 0.03 & 0.15 & 0.18 \\
Temora V-VI & 0.39 & 0.07 & 0.06 & 0.60 & 0.15 \\
Remaining copepod5 & 0.32 & 0.79 & 0.69 & 0.18 \\
Total & 1.00 & 0.87 & & & 0.15 \\
\hline
\end{tabular}

Table 5. Sagitta elegans. Percentage, within different prey categories, of prey items found singly or together with 1, 2, or 3 or more other prey (not necessarily of the same category)

\begin{tabular}{|c|c|c|c|c|c|c|c|c|c|c|c|c|c|}
\hline & \multicolumn{3}{|c|}{$\begin{array}{c}\text { April } \\
\text { Old generation }\end{array}$} & \multicolumn{3}{|c|}{$\begin{array}{c}\text { April } \\
\text { New generation }\end{array}$} & \multicolumn{3}{|c|}{ July } & \multicolumn{2}{|c|}{ October } & \multicolumn{2}{|c|}{ December } \\
\hline & Cal. & Tem. & Cop. & Cal. & Tem. & Cop. & Cal. & Tem. & Cop. & Cal. & Cop. & Cal. & Cop. \\
\hline Single & 80 & 55 & 52 & 100 & 92 & 85 & 78 & 39 & 37 & 99 & 97 & 97 & 94 \\
\hline 1 & 14 & 26 & 30 & & 8 & 13 & 14 & 20 & 17 & 1 & 3 & 3 & 6 \\
\hline 2 & 2 & 10 & 10 & & & 3 & 6 & 15 & 12 & & & & \\
\hline$\geq 3$ & 3 & 9 & 9 & & & & 2 & 27 & 34 & & & & \\
\hline $\mathrm{n}$ & 229 & 204 & 143 & 7 & 24 & 237 & 64 & 92 & 684 & 439 & 22 & 95 & 16 \\
\hline
\end{tabular}

Table 6. Sagitta setosa. Percentage, within different prey categories, of prey items found singly or together with 1,2 or 3 or more prey items (not necessarily of the same category)

\begin{tabular}{|c|c|c|c|c|c|c|c|}
\hline \multirow[b]{2}{*}{ Single } & \multicolumn{4}{|c|}{$\begin{array}{c}\text { October } \\
\text { Cop. Naup. S.s. ' Unident. }\end{array}$} & \multicolumn{3}{|c|}{$\begin{array}{c}\text { December } \\
\text { Cop. Naup. Unident. }\end{array}$} \\
\hline & 79 & 76 & 69 & 90 & 88 & 92 & 87 \\
\hline 1 & 17 & 15 & 31 & 8 & 10 & 8 & 13 \\
\hline 2 & 3 & 7 & & 1 & & & \\
\hline$\geq 3$ & & 2 & & 1 & & & \\
\hline $\mathrm{n}$ & 622 & 348 & 65 & 178 & 162 & 206 & 61 \\
\hline
\end{tabular}

sampling time compared to swallowing and transport time of food to the middle and posterior part of the gut. The swallowing process of a Calanus $\mathrm{V}$ by a $22 \mathrm{~mm}$ long $S$. elegans took $8 \mathrm{~min}$ in the laboratory at $6{ }^{\circ} \mathrm{C}$ (pers. obs.). The prey is then, within 30 to $50 \mathrm{~min}$, transported, largely undigested, to the posterior part of the gut, where digestion takes part (pers. obs. of $10 \mathrm{~S}$. elegans eating Calanus at $6^{\circ} \mathrm{C}$ ). Pearre (1973) and Feigenbaum (1982) (after omitting prey in the forward part of the gut) also neglected cod-end feeding in $S$. elegans. Voiding and defaecation of gut content may perhaps occur but information concerning this is scarce. Sullivan (1980) observed no loss of gut content in $S$. elegans during application of preservatives but gave no detailed information. By using the mandible counting method even the nauplii and multiple prey defaecated together could be counted, as mandibles are not digested. Some papers report starvation times of $24 \mathrm{~h}$ or more before the start of digestion time experiments. Such starving might bias the results and therefore in this study the $S$. elegans were not given food from about $1300 \mathrm{~h}$ (a time when feeding has usually stopped in nature) until the experiments started in the evening (when it usually starts in nature). Cosper \& Reeve (1975) found that a starvation of $48 \mathrm{~h}$ in $S$. hispida appeared to cause more variability in DT compared to $24 \mathrm{~h}$, but that the term 'starvation' probably was not applicable to periods less than $24 \mathrm{~h}$.

\section{Sagitta elegans}

Decreased feeding activity during the day in Sagitta elegans has been reported by Wimpenny $(1937,1938)$, Rakusa-Suszczewski (1969), Pearre (1973), Sullivan (1980), Feigenbaum (1982) and Ohman (1986). In this study, the diel feeding behaviour of $S$. elegans varied with season, showing a significant decline in feeding during the day in July, but not in December. In April and October intermediate feeding behaviour was found. Since Calanus was the dominant food item in 
both October and December, the absence of a daytime decrease in feeding in December could therefore not be due to a shift in diet alone. Pearre (1973) found a similar difference in feeding behaviour in July and December in Bedford Basin and he suggested this could have been due to greater light intensity in July leading to feeding inhibition. The mode in which this might operate is, however, obscure. Chaetognaths are ambush feeders and the encounter rate of prey should increase at times when prey are more active. If the prey perform vertical migration during the dark period, higher feeding activity among chaetognaths could be expected at that time. A shorter dark period would then tend to shorten the feeding time available for Sagitta. Reeve (1980) suggested that chaetognaths were adapted to feeding on very localized concentrations of food (by having a large gut capacity), interspersed by much longer (in both temporal and spatial terms) periods of food 'vacuum'. Both the occurrence of multiple prey and low FR found in this study as well as the fact that $S$. elegans can survive starvation for over $14 \mathrm{~d}$ (Kotori 1976) may indicate that $S$. elegans can utilize patchy food concentrations. In the DT experiments it was often observed that $S$. elegans constantly failed in catching prey even when the head was surrounded by high concentrations of copepods (this was observed also in complete darkness, using IR light and an IR viewer to observe the Sagitta). Perhaps these high concentrations of prey disturbed the $S$. elegans, since chaetognaths are reported to react to vibration stimuli when hunting (see Feigenbaum \& Maris 1984). On the other hand, if $S$. elegans is an inefficient hunter, i.e. needs many trials to catch a prey, searching for local concentrations of prey might be favourable.

Feigenbaum (1982) gave a DT of $10.2 \mathrm{~h}$ (mean of 17 measurements, range of 4.6 to $16.7 \mathrm{~h}$ ) at $0^{\circ} \mathrm{C}$, based on copepods of different sizes and numbers and Sagitta elegans starved for 2 to $4 \mathrm{~d}$ before the experiments started. Kuhlmann (1977) reported a DT of $2.5 \mathrm{~h}$ at $15^{\circ} \mathrm{C}$ for $S$. elegans eating copepods (based on 12 measurements according to Kuhlmann 1976). The DT data obtained in this study indicate that DT varies with prey category. Reeve (1980) related in laboratory experiments an increase in DT to increased food size over the early part of the life of S. hispida. He also found that DT was directly proportional to the number of food items in the older individuals. If this is true for $S$. elegans, the occurrence of multiple prey in this study would cause a slight overestimation of FR. Since prey occurring together will have longer DT, they will give a higher mean NPC value than if occurring singly and with a lower DT value. This increase in mean NPC, caused by the longer residence time of multiple prey, has not been corrected for by using a higher DT value in the FR calculations. DT is undoubtedly dependent also on temperature as indicated by the available data for S. elegans (see also Pearre 1981, Ohman 1986). No information is available concerning the effect of the nutritional composition of prey on DT. The Calanus used in these experiments were all rich in oil and after the faecal pellets had been dropped, oil originating from the prey could sometimes be seen in the $S$. elegans gut indicating a longer digestion time for oil.

The feeding rates given in Table 4 should be interpreted with caution, primarily due to the few DT data and absence of vertical distribution data of Sagitta elegans and thus limited knowledge of temperatures experienced by $S$. elegans during digestion. The feeding rates calculated in this study have been limited to numbers until the above information for $S$. elegans in Gullmarsfjorden is available. The high occurrences in the old generation in April of multiple prey and small copepods as well as high feeding rates are notable (also noted by Ohman 1986). These results may be correlated to higher encounter rates of prey or less discriminating feeding behaviour due to higher food requirements (due to reproduction). Temperature, which is low in April, does not explain these results. During spring and summer the feeding rates varied between 0.9 and 0.7 prey in the new generation, and a marked decrease down to 0.2 prey was found during autumn and winter. This decrease is correlated to a shift in diet to larger prey (Calanus), an increase in size, and most likely to a deeper vertical distribution of $S$. elegans. The larger size enables $S$. elegans to eat Calanus, indicated by the fact that none of the short specimens in the new generation in April and July ate Calanus. Pearre (1980) showed that head width was correlated positively to prey size. Jakobsen (1971), investigating the daytime vertical distribution of $S$. elegans in Oslofjorden, found that of the 18 to $28 \mathrm{~mm}$ long specimens, $92 \%$ occurred deeper than $50 \mathrm{~m}$. Smaller prey living in the upper water layer will not be encountered by S. elegans at the same rate as earlier if diel vertical migration is absent or decreases during autumn and winter. The question of selectivity and encounter rate of different prey categories cannot, however, be carried further here due to the lack of vertical distribution data of prey and predators in Gullmarsfjorden.

Rakusa-Suszczewski (1969) found that Calanus finmarchicus was the predominant food of Sagitta elegans in the northern part of the North Sea during autumn whereas the main food species in the central and western part were Centropages typicus and Temora longicornis. He also pointed out the change in preferred food size as the chaetognaths increased in size and thereby the importance of knowing the temporal size distribution of predator and prey in different areas (see also Pearre 1980). 


\section{Sagitta setosa}

Decreased feeding during the day in Sagitta setosa has been reported by Wimpenny $(1937,1938)$, Parry (1944), Mironov (1960) and Rakusa-Suszczewski (1969). S. setosa showed little feeding during daytime in October and especially in December If light is important (directly or indirectly) in controlling feeding behaviour, $S$. setosa might still be affected by light during December, as it is a surface-layer species, in contrast to $S$. elegans. The morning feeding observed in December may be correlated to early feeding in the day and/or the length of the dark period. Pearre (1973) suggested that in seasons when the dark period becomes longer than the digestive period, some of the early feeders might hunt a second time.

Multiple prey are generally more common in October which might, as in Sagitta elegans in April, reflect an increased food requirement due to reproduction. $S$. setosa eats smaller food items than $S$. elegans and also has a more variable diet. The somewhat higher total mean NPC in December (due to mean NPC of nauplii) is not likely to reflect a higher FR. In fact, $S$. setosa experiences a decrease in temperature in the upper $20 \mathrm{~m}$ of approximately $8^{\circ} \mathrm{C}$ from October to December which would affect DT greatly. It is therefore likely that FR decreases during autumn and winter also for $S$. setosa. The roughly estimated value of 2.3 in October is much higher than any value for $S$. elegans. The need for new DT measurements for $S$. setosa at different temperatures and seasons is obvious, in order to draw further conclusions from these data.

\section{Cannibalism and fish larvae predation}

The occurrence of cannibalism in Sagitta setosa in October and its absence in December is notable. The low rate of cannibalism in December may be explained by the absence of small $S$. setosa. Kuhlmann (1977) reported a DT of 200 to $300 \mathrm{~min}$ for Sagitta prey in Sagitta at $15^{\circ} \mathrm{C}$ (giving no further details). Assuming a DT of $4.2 \mathrm{~h}(250 \mathrm{~min})$ a FR of 0.07 is obtained for $S$. setosa as prey during October (water temperature was $14^{\circ} \mathrm{C}$ in the upper $20 \mathrm{~m}$ ). A FR of 0.07 prey ind ${ }^{-1} \mathrm{~d}^{-1}$ for the whole population means that if only half of the population were cannibals and eating the other half at a constant rate of 0.14 ind $\mathrm{d}^{-1}$, the prey $S$. setosa would be reduced by $50 \%$ within $4 \mathrm{~d}$. This assumed example may indicate that it is not unlikely that the sharp decrease in $S$. setosa during autumn as shown in Øresland $(1983,1985)$ could be due partly to cannibalism. However, more information throughout the breeding period is needed if more meaningful calculations on the effect of cannibalism are to be made. The low occur- rence of cannibalism in $S$. elegans may perhaps be due to low encounter rate of small specimens by the larger ones, which have a deeper vertical distribution. In $S$. setosa, on the other hand, different size classes may be much less separated vertically, due to this being primarily a surface-layer species. This may also explain why no $S$. setosa were taken by $S$. elegans. The difference in cannibalism is notable, and it does not support the hypothesis proposed by Stone (1965) (statistical support for this was provided by Pearre 1982) that cannibalism increases with species size (see also Feigenbaum \& Maris 1984). Feigenbaum (1982) found little cannibalism in $S$. elegans in early spring in Vineyard Sound, while Pearre (1981) found that cannibalism played an important part in the energy intake of the larger stages in December in Bedford Basin.

The question of predation on fish larvae by Sagitta elegans and $S$. setosa has been discussed by e.g. Lebour (1922, 1923), Tungate (1975), Kuhlmann (1977), and Alvariño (1985). Sprattus sprattus and Scomber scombrus are some of the most common fish larvae on the Swedish west coast. The newly hatched larvae are found in greatest numbers in June (Lindquist 1970), a month not included in this study. Kuhlmann (1977) thought that predation on fish larvae would occur only during the first days after the larvae had hatched. Tungate (1975) concluded that Sagitta spp. would have insignificant effect on the mortality rates of plaice larvae due to the latters large size. No fish larvae were found in any Sagitta in this study.

\section{CONCLUSIONS}

This initial study on predation by chaetognaths in Gullmarsfjorden was done in order to obtain some basic estimates of diet, feeding behaviour and feeding rates and their variation throughout the year. The need for further DT data and vertical distribution and migration data has been pointed out. The obtained FR of 1.0 to 0.2 items $\mathrm{d}^{-1}$ for Sagitta elegans does not perhaps give the impression that the species should be particularly important as a predator, when other predators like Aurelia aurita and Cyanea capillata obviously have a much higher FR. However, the dominance in numbers of chaetognaths over other pelagic predators and the presence of $S$. elegans throughout the year indicate the importance of chaetognaths. Good quantitative estimates of the abundance of chaetognaths, considering patchy distribution and possible occurrence close to the bottom for S. elegans (see Hesthagen 1973, Oug 1977), have not yet been obtained in Gullmarsfjorden.

Acknowledgements. Professor Hans Ackefors, Dr Lars Hemroth and Dr Sifford Pearre Jr. gave helpful comments on the manuscript. The figures were drawn by Bibbi Mayrhofer and the English was reviewed by Dr Klaus Koop. Field work was 
carried out at Kristineberg Marine Biological Station. Laboratory experiments were conducted at Tjärnö Marine Biological Station. Financial support was given by Gustaf Lindströms Minnesfond and Kristineberg Marine Biological Station.

\section{LITERATURE CITED}

Alvariño, A. (1985). Predation in the plankton realm; mainly with reference to fish larvae. Inv. Mar. CICIMAR 2: 1-122

Bajkov, A. D. (1935). How to estimate the daily food consumption of fish under natural conditions. Trans. Am. Fish. Soc. 65: $288-289$

Canino, M. F., Grant, G. C. (1985). The feeding and diet of Sagitta tenuis (Chaetognatha) and the Lower Chesapeake Bay. J. Plankton Res. 7: 175-188

Cosper, T. C., Reeve, M. R. (1975). Digestive efficiency of the chaetognath Sagitta hispida Conant. J. exp. mar. Biol. Ecol. 17: 33-38

Drits, A. V. (1981). Some feeding regularities in Sagitta enflata. Okeanologiya 21: 882-888

Ehrenbaum, E., Strodtmann, S. (1904). Eier und Jugendformen der Ostseefische. I Ber wiss. Meeresunters. VI. Abt. Helgoland 57-126

Feigenbaum, D. L. (1982). Feeding by the chaetognath, Sagitta elegans, at low temperatures in Vineyard Sound, Massachusetts. Limnol. Oceanogr. 27: 699-706

Feigenbaum, D. L., Maris, R. C. (1984). Feeding in Chaetognatha. Oceanogr. Mar. Biol. A. Rev. 22: 343-392

Fulton, R. S. III (1984). Effects of chaetognath predation and nutrient enrichment on enclosed estuarine copepod communities. Oecologia (Berl.) 62: 97-101

Furnestin, J. (1938). Influence de la salinité sur la répartition du genre Sagitta dans l'Atlantique nord-est (juillet-aoutseptembre 1936). Rev. Trav. Off. Pêches maritim. 11 $425-439$

Hesthagen, I. H. (1973). Diurnal and seasonal variations in the nearbottom fauna - the hyperbenthos - in one of the deeper channels of the Kieler Bucht (Western Baltic). Kieler Meeresforsch. 29: 116-140

Jakobsen, T. (1971). On the biology of Sagitta elegans Verrill and Sagitta setosa J. Müller in inner Oslofjord. Norw. J. Zool. 19: 201-225

Kimmerer, W. J. (1984). Selective predation and its impact on prey of Sagitta enflata (Chaetognatha). Mar. Ecol. Prog Ser. 15: 55-62

Kotori, M. (1976). The biology of Chaetognatha in the Bering Sea and the northern North Pacific Ocean, with emphasis on Sagitta elegans. Mem. Fac. Fish. Hokkaido Univ. 23: 95-183

Kuhlmann, D. (1976). Experimentelle Untersuchungen zum Nahrungserwerb der Chaetognathen Sagitta setosa J. Müller und Sagitta elegans Verrill unter besonderer Berücksichtigung ihres Verhaltens gegenüber Fischbrut. Diplomarbeit, Christian-Albrechts-Universität Kiel

Kuhlmann, D. (1977). Laboratory studies on the feeding behavior of the chaetognaths Sagitta setosa J. Müller and $S$. elegans Verrill with special reference to fish eggs and larvae as food organisms. Kieler Meeresforsch. 25: $163-171$

Lebour, M. V. (1922). The food of plankton organisms. J. mar biol. Ass. U.K. 12: 644-677

Lebour, M. V. (1923). The food of plankton organisms. II. J. mar. biol. Ass. U.K. 13: 70-92

Lindquist, A. (1970). Zur Verbreitung der Fischeier und Fischlarven im Skagerak in den Monaten Mai und Juni. Inst. Mar. Res. Lysekil Ser Biol. Rep. 19: 1-82
Mironov, G. N. (1960). The feeding of plankton predators. II. The feeding of Sagittae. Trudy sevastopol' biol. Sta. 13: 78-88

Motoda, S. (1959). Devices of simple plankton apparatus. Mem. Fac. Fish. Hokkaido Univ. 7: 73-94

Nagasawa, S. (1984). Laboratory feeding and egg production in the chaetognath Sagitta crassa Tokioka. J. exp. mar. Biol. Ecol. 76: 51-65

Nagasawa, S. (1985). The digestive efficiency of the chaetognath Sagitta crassa Tokioka, with observations on the feeding process. J. exp. mar. Biol. Ecol. 87: 271-281

Nagasawa, S., Marumo, R. (1982). Vertical distribution of epipelagic chaetognaths in Suruga Bay, Japan. Bull. Plankt. Soc. Japan 29: 9-23

Nagasawa, S., Marumo, R. (1984). Feeding habits and copulation of the chaetognath Sagitta crassa. La mer 22: 8-14

Ohman M. D. (1986). Predator-limited population growth of the copepod Pseudocalanus sp. J. Plankton Res. 8: 673-713

Øresland, V (1983). Abundance, breeding and temporal size distribution of the chaetognath Sagitta setosa in the Kattegat. J. Plankton Res. 5: 425-439

Øresland, V. (1985). Temporal size and maturity-stage distribution of Sagitta elegans and occurrence of other chaetognath species in Gullmarsfjorden, Sweden. Sarsia 70: $95-101$

Oug, E. (1977). Faunal distribution close to the sediment of a shallow marine environment. Sarsia 63: 115-121

Parry, D. A. (1944). Structure and function of the gut in Spadella cephaloptera and Sagitta setosa. J. mar. biol. Ass. U.K. 26: $16-36$

Pearre, S., Jr. (1973). Vertical migration and feeding in Sagitta elegans Verrill. Ecology 54: 300-314

Pearre, S., Jr. (1980). Feeding by Chaetognatha: the relation of prey size to predator size in several species. Mar. Ecol. Prog. Ser. 3: 125-134

Pearre, S., Jr. (1981). Feeding by Chaetognatha: energy balance and importance of various components of the diet of Sagitta elegans. Mar. Ecol. Prog. Ser. 5: 45-54

Pearre, S., Jr. (1982). Feeding by Chaetognatha: Aspects of inter- and intra-specific predation. Mar. Ecol. Prog. Ser. 7: $33-45$

Rakusa-Suszczewski, S. (1969). The food and feeding habits of Chaetognatha in the seas around the British Isles. Pol. Arch. Hydrobiol. 16: 213-232

Reeve, M. R. (1980). Comparative experimental studies on the feeding of chaetognaths and ctenophores. J. Plankton Res. 2: $381-393$

Southward, A. J., Barret, R. L. (1983). Observations on the vertical distribution of zooplankton, including post-larval teleosts, off Plymouth in the presence of a thermocline and a chlorophyll-dense layer. J. Plankton Res. 5: 599-618

Stone, J. H. (1965). The Chaetognatha community of the Agulhas Current: its structure and related properties. Ph.D. thesis, University of Cape Town, South Africa

Sullivan, B. K. (1980). In situ feeding behavior of Sagitta elegans and Eukrohnia hamata (Chaetognatha) in relation to the vertical distribution and abundance of prey at Ocean Station 'P' Limnol. Oceanogr 25: 317-326

Terazaki, M., Marumo, R. (1982). Feeding habits of meso- and bathypelagic Chaetognatha, Sagitta zetesios Fowler. Oceanol. Acta 5: 461-464

Tungate, D. S. (1975). The distribution and abundance of chaetognaths and the ctenophore Pleurobrachia pileus in the southern North Sea in 1968 and their importance as predators of plaice eggs and larvae. Fish. Lab. Lowestoft, Suffolk, Fish. Lab. Tech. Rep. Ser. 18: 1-30 
Wimpenny, R. S. (1937). The distribution, breeding and feeding of some important plankton organisms of the southwest North Sea in 1934. Fishery Invest., Lond. (Ser. 2), 15: $1-53$
Wimpenny, R. S. (1938). Diurnal variation in the feeding and breeding of zooplankton related to the numerical balance of the zoo-phytoplankton community. J. du Conseil 13: $323-327$

This article was submitted to the editor; it was accepted for printing on May 4, 1987 